\title{
Survey on Android Base Smart City Nagpur App
}

\author{
V.P. Balpande ${ }^{1^{*}}$, L. Lende ${ }^{2}$, R. Raut ${ }^{3}$, R. Deshpande ${ }^{4}$, S. Thakur ${ }^{5}$, S. Majarkhede ${ }^{6}$ \\ 1* Dept. of CSE, Priyadarshini J.L. College of Engg.,(Rashtrasant Tukadoji Maharaj Nagpur University), Nagpur, India \\ ${ }^{2}$ Dept. of CSE, Priyadarshini J.L. College of Engg.,(Rashtrasant Tukadoji Maharaj Nagpur University), Nagpur, India \\ ${ }^{3}$ Dept. of CSE, Priyadarshini J.L. College of Engg.,(Rashtrasant Tukadoji Maharaj Nagpur University), Nagpur, India \\ ${ }^{4}$ Dept. of CSE, Priyadarshini J.L. College of Engg.,(Rashtrasant Tukadoji Maharaj Nagpur University), Nagpur, India \\ ${ }^{5}$ Dept. of CSE, Priyadarshini J.L. College of Engg.,(Rashtrasant Tukadoji Maharaj Nagpur University), Nagpur, India \\ ${ }^{6}$ Dept. of CSE, Priyadarshini J.L. College of Engg.,(Rashtrasant Tukadoji Maharaj Nagpur University), Nagpur, India
}

*Corresponding Author: vpbhute@gmail.com, Tel: +919881977512

Available online at: www.isroset.org

Received 22/Dec/2017, Revised 07/Jan/2018, Accepted 20/Jan/2018, Online 28/Feb/2018

\begin{abstract}
Android applications have become a trend these days. Our lives have become much reliable and enjoyable because of some famous applications with their functional tactics. This app enable to service delivery and information sharing using mobile technology. This app makes daily life of people easier by providing solution to the real life problem faced by people. Manual complaint can be overcome by the feature provided in this app. People can search the bus running between the source and destination. People can find out tourist spot to visit. So the main objective of this app is to provide solution to the above problem and encouraging the concept of smart city.
\end{abstract}

Keywords- smart city, complaint, transport, tourism.

\section{INTRODUCTION}

The government of India had started the initiative of Smart city project under which various cities where selected for this project. Nagpur was one of the cities that were selected. City which uses information and communication technology to make its offered infrastructure, its component and services provided to public become more interactive and efficient and makes its citizen more aware of them is called as smart city. Our app supports the concept of smart city.

This app can improve quality of life of citizens' city apps should provide services which helps them in their daily life. Services which allow them to find locations browse information about public private bodies, to share information among citizens. This city app can support social activities in city and to bring some basic problems in light.

Mobile apps are becoming a new front line for city services; smart phone apps can centralize the point of contact for city resident and encourage collaboration in services in city. The extended use of smart phones - cellphones with high-speed internet access and geological location technology is transforming the life of people.

This app make daily life of people easier by providing solution to the real life problem faced by people such as where to report the complaint, how to get information regarding bus arrival time, buses running between source to destination, what are the famous places in Nagpur and nearby, how to go there. The main motive of app is to offer the possibility of MONETIZE the open data. Improve the estimated services to the citizen is one sustainable way to the economic and social development.

The app brings together all city services; immediate with traveler interest which fosters the financial sector and generate value to citizens. The city open-data will provide valuable information for citizens improving their quality of life and generating wealth.

India has third largest users of the smart phones. All these mentioned services can be implemented with Android app for supporting the momentum of digital India. This app can promote digital proficiency among the citizens.

Smart Cities gained importance by providing the services which connect people to the technology making their life easier.. It aims at increasing citizens' quality of life, and improving the ability and quality of the services provided by governing bodies and businesses.

The organization of the paper is as follow, Section I contains the introduction of Android Based Smart City Nagpur App, Section II contain the related work for the Android Based 
Smart City Nagpur App, Section III contain the proposed system of Android Based Smart City Nagpur App, Section IV concludes research work with future directions.

\section{RELATED WORK}

In [1], the authors had developed mobile application that informs citizens about key aspects of the city, to take initiative to social activities and to keep them updated. Also bring people together to solve basic problems collectively. . Following are the features provided by the app social, city hospital, theaters, Government Offices, bus timetable, banks, colleges and offline map. Project comes with android app which includes information about significant services in the city. This app communicates with server with the help of internet to update information automatically. The citizens access information in one touch in their android device. Also, citizens use location services in the city with the help of offline map in app.

In [2], the authors had proposed system an android application mobile interface that is used to lodge complaints. The main idea is to make use of the existing web framework and to provide simple, reasonable and rapid mode of complaint registration. The proposed system will facilitate the citizens of city to lodge complaints anytime, anywhere. Mobile application helps the citizen to register their complaints about problems in their ward through a mobile application. Mobile application provides citizens to deliver his complaints and problems to Municipal Corporation as well as let the municipal authorities to look at problem and provide solution to the problem. The application provides an interface to register the complaint and take follow of it .The interface had camera module which help to take a snap of any generalized problem that people are encountered and will post this photo along with the complaint. The location of complaint is tracked by Global Positioning System (GPS). This module provides exact location of that appropriate problem. Thus complaint, once registered, will be rechanneled to specific department of Municipal Corporation for example; a complaint about garbage will be redirected to cleaning department. It is a single mark web and mobile based complaint management system linking all departments in the organization and could take administration capability to the next level. The system provides advantages to the organization, employees and the citizen. One of the key features is the provision for citizens /consumers /employees to lodge complaints/grievances using their mobile phones with a software application specially designed to file complaints.

In [3], authors proposed an application "Tourist assistant TAIS" that is related to "Travel Guides" category suggest the tourist interest around. Information about tourist attractions is obtained from different internet sources. The application consists of set of services that interact with each other for providing the travel endorsement about tourist attraction that is better to see around.

There are various features provided such as client application, tourist attraction information service, recommendation service, region context service, ride-sharing service and public transport service. The tourist can get detailed information about the selected destination, browse attraction reaching path that is proposed by the system route to an attraction and estimate it. The traveller has possibility to estimate images using following options: "like images", "dislike images", "this image is not applicable" to the attraction. Based on these evaluations the recommendation service will re-order images for this or another traveller next time.

In [4], authors proposed an android application which gives the information about bus system which provides details about bus numbers and let you know about bus tracks both online and offline. The application deals with services like appropriate distance and fare between source and destination to user. This system in which user is provided with required bus timings according to his need for a specific source. The proposed system provide the user with accurate results, a proper input from the user is necessary to get the accurate timings of bus schedules user should provide accurate input of his required source. Along with this he can also get the fare of the required route which he wishes to travel.

\section{Proposed SySTEM}

We have studied all existing system and found that user needs to maintain different application for complaint registration, tourism and transport. So in order to reduce the overhead of user we have proposed system that combines the above mentioned features. This app is easy to use and resolve the problem of citizens. The complaint registration tab provides proper channel to both citizens and NMC for resolving the issues faced by the citizens. The transport tab provides detail about the arrival and departure time of star bus. The transport tab provides an easy access to the details of famous tourist places.

\section{CONCLUSION}

The research paper provides the brief idea about the problems faced by citizens and best way to solve these issues is using technology. The proposed system is a mobile app that gives solution to all the mentioned problems faced by the citizens in easy and efficient way. The complaint tab has limitation that it is not verifying whether the serviceman is actually resolving the complaint or not. The transport tab doesn't provide the real time tracking of star buses. The complaint tab can be enhanced by adding verification whether serviceman is resolving the complaint tab or not. The transport tab can be enhanced by providing real time tracking of star buses. 


\section{IV.REFERENCES}

[1]. 1.Smart City (Karad) Android Application Prashant Ghadage, Sagar Yadav, Swarel Jadhav, Truptej Patil Professor.Shinde R.S., Dept. Of Computer Science \&Engineering, DACOE Karad, Maharashtra, India country

[2]. 2.Transportation android mobile application for Pune city Amol Jaybhaye, Jagdish Kate, Ajinkya Joshi, Viraj Patil Multidisciplinary Journal of Research in Engineering and Technology, Volume 3, Issue 2, Pg.953-957

[3]. 3. Mobile Application Interface to Register Citizen Complaint Dhaval Gherwada, Vipul Shah,,Dip Shah, Prof.Harsh N.Bhor, B.E IT student, KJSIEIT, Sion, Mumbai, Asst. Professor, KJSIEIT,Sion ,Mumbai,Maharashtra,India.

[4]. 4.Mobile Application for Guiding Tourist Activities: Tourist Assistant-TAIS Alexander Smirnow, Alexey Kashevnik, Nikolay Shilov, Nikolay Teslya Anton Shabaev, SPIIRAS,St.Petersburg,Russia,ITMO University ,St.Petersburg,Russia Petrozavodsk State University (PetrSU)\{smir,Alexey,nick,teslya\}@iias.spb.su,ashaev@pestru.ru

\section{Authors Profile}

Mr V.P. Balpande pursued Bachelor of Engineering from Yeshwantrao Chavan College of Engineering Nagpur in 1996 and Master of Technology from Rashtrasant Tukadoji Maharaj Nagpur University in year 2008. She has pursued Ph.D. and currently working as Head of Department of Computer Science \& Engineering,PJLCOE,Nagpur

Leena Lende is pursuing her bachelor of engineering in Computer Science \& Engineering from Priyadarshini J.L of Engineering, Rashtrasant Tukadoji Maharaj Nagpur University, Nagpur440009, India

Ravina Raut is pursuing her bachelor of engineering in Computer Science \& Engineering from Priyadarshini J.L of Engineering, Rashtrasant Tukadoji Maharaj Nagpur University, Nagpur440009, India

Renuka Deshpande is pursuing her bachelor of engineering in Computer Science \& Engineering from Priyadarshini J.L of Engineering, Rashtrasant Tukadoji Maharaj Nagpur University, Nagpur440009, India
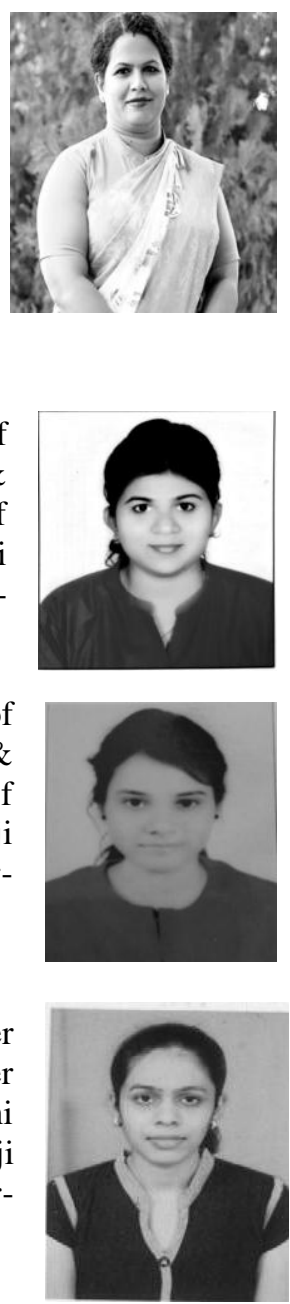

Shikha Thakur is pursuing her bachelor of engineering in Computer Science \& Engineering from Priyadarshini J.L of Engineering, Rashtrasant Tukadoji Maharaj Nagpur University, Nagpur440009, India

Sanjog Majarkhede is pursuing his bachelor of engineering in Computer Science \& Engineering from Priyadarshini J.L of Engineering, Rashtrasant Tukadoji Maharaj Nagpur University, Nagpur-440009, India

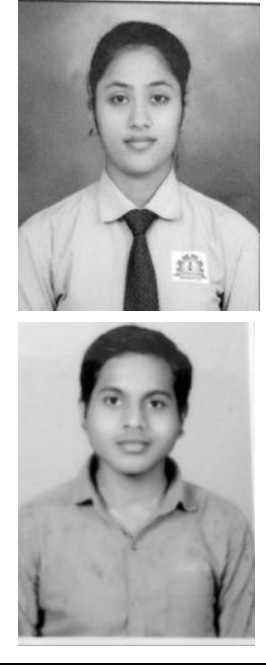

